
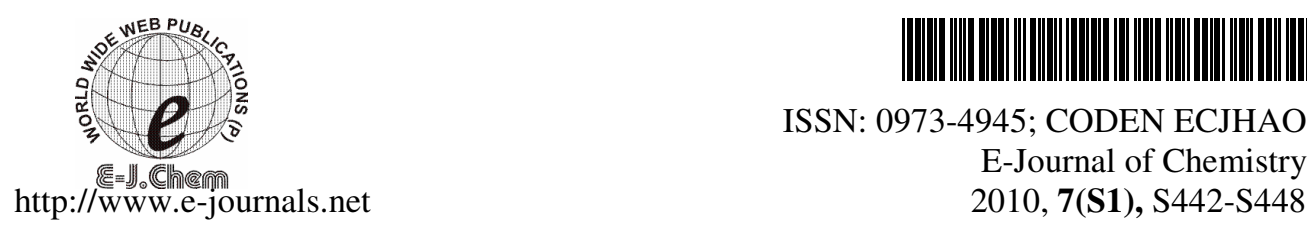

ISSN: 0973-4945; CODEN ECJHAO

E-Journal of Chemistry

2010, 7(S1), S442-S448

\title{
Corrosion Inhibition and Adsorption Characteristics of Tarivid on Mild Steel in $\mathrm{H}_{2} \mathrm{SO}_{4}$
}

\author{
N. O. EDDY and E. E. EBENSO* \\ Department of Chemistry, Ahmadu Bello University, Zaria, Kaduna State, Nigeria \\ *Department of Chemistry, North West University (Mafikeng Campus) \\ Private Bag X2046, Mmabatho 2735, South Africa \\ eno.ebenso@nwu.ac.za
}

Received 9 October 2009; Accepted 5 December 2009

\begin{abstract}
The corrosion inhibition and adsorption characteristics of (+/-)-9-fluoro2,3-dihydro-3-methyl-10-(4-methyl-1-piperazinyl)-7-oxo-7H-pyrido[1,2,3-de]-1,4benzoxazine-6-carboxylic acid (Tarivid) on the corrosion of mild steel has been studied using thermometric and gasometric methods. The study reveals that tarivid inhibits the corrosion of mild steel in $\mathrm{H}_{2} \mathrm{SO}_{4}$. The values of inhibition efficiency of tarivid were found to increase as its concentration increased but decreased with increase in temperature. Activation energies of the inhibited corrosion of mild steel ranged from 39.05 to $50.61 \mathrm{~kJ} / \mathrm{mol}$. Values of enthalpy change and free energy of adsorption were negative which indicated exothermic and spontaneous adsorption process. Physical adsorption mechanism is proposed from the obtained kinetic and thermodynamic parameters. Langmuir adsorption isotherm model is obeyed from the fit of the experimental data.
\end{abstract}

Keywords: Corrosion inhibition, Mild steel, Adsorption, Langmuir adsorption isotherm, Tarivid.

\section{Introduction}

Mild steel is widely used in most industries because of their special properties. However, the metal corrodes when it comes in contact with acid solutions during processes such as acid cleaning, prickling, etc ${ }^{1-4}$. The use of a suitable corrosion inhibitor is therefore needed for the protection of this valuable metal.

Several inhibitors in use are either synthesized from cheap raw materials or are chosen from compounds having heteroatoms in their electron rich aromatic or long chain carbon system $^{5}$. A few investigations have been reported on the use of antibacterial drugs as corrosion inhibitors. Rhodanine azosulpha drugs have been reported as corrosion inhibitors for the corrosion of 304 stainless steel in $\mathrm{HCl}$ solutions using weight loss and potentiostatic polarization techniques by Abdallah ${ }^{6}$. They inhibited the corrosion by parallel adsorption on 
the surface of steel due to the presence of more than one active centre in the inhibitor. Abdallah $^{7}$ also studied some antibacterial drugs viz. ampicillin, cloxacillin, flucloxacillin and amoxicillin as corrosion inhibitors for aluminium in $\mathrm{HCl}$ solutions using hydrogen evolution, weight loss and potentiostat polarization techniques. The inhibitive effect of four sulpha drug compounds viz. sulfaguanidine, sulfamethazine, sulfamethoxazole and sulfadiazine on mild steel corrosion in $\mathrm{HCl}$ solutions was reported using both weight loss and galvanostatic polarization ${ }^{8}$. The sulfa drugs have a large number of functional adsorption centers (e.g. $-\mathrm{NH}_{2}$ group, $-\mathrm{SO}_{2}-\mathrm{NH}$ - group, $\mathrm{O}$ and/or $\mathrm{N}$-heteroatoms and aromatic rings). They are strongly basic and are readily soluble in the acid medium. Rhodanine has also been reported as corrosion inhibitor for mild steel in $\mathrm{HCl}$ by Solmaz et. al. ${ }^{9}$ using potentiodynamic polarization, electrochemical impedance spectroscopy etc. Most of the drugs used play important roles in biological reactions because of their anticonvulsant, antibacterial, antidiabetic, inhibitive to mycobacterium tuberculosis and other properties ${ }^{10,11}$. The choice of some of the drugs used as corrosion inhibitors is based on the following facts (a) the molecules have oxygen, nitrogen and sulphur as active centres, (b) they are healthy and reportedly very important in biological reactions (i.e. not hazardous and environmentally friendly) and (c) they can be easily produced and purified. In view of the above, the objective of the present work is to study the corrosion inhibitive action of tarivid (another drug) on mild steel in acidic medium using thermometric and gasometric (hydrogen evolution) method.

Tarivid, (Scheme 1) (+/-)-9-fluoro-2, 3-dihydro-3-methyl-10-(4-methyl-1-piperazinyl)7-oxo-7H-pyrido[1,2,3-de]-1,4-benzoxazine-6-carboxylic acid [molecular mass of tarivid is $361.368 \mathrm{~g} / \mathrm{mol}$ ] is an antibiotic normally used for the treatment of some infections. The chemical structure of the compound is shown below. From the Figure below, it can be seen that tarivid has heteroatoms $(\mathrm{N}$ and $\mathrm{O}$ ) in its aromatic ring system indicating that it may be a good corrosion inhibitor. Therefore, our present study seeks to investigate the inhibitive properties of tarivid for the corrosion of mild steel in $\mathrm{H}_{2} \mathrm{SO}_{4}$.

\section{Experimental}<smiles>C[C@@H]1COc2c(N3CCN(C)CC3)c(F)cc3c(=O)c(C(=O)O)cn1c23</smiles>

Materials used for the study were mild steel sheets of composition (wt \%) Mn (0.6), $\mathrm{P}(0.36)$, $\mathrm{C}(0.15)$ and $\mathrm{Si}(0.03)$ and dimension, $5 \times 4 \times 0.11 \mathrm{~cm}$. Each coupon was degreased by washing in ethanol, dried in acetone and preserved in a desiccator. The inhibitor (tarivid) was supplied by Pubmed pharmaceutical company. All reagents used for the study were analar grade. Double distilled water was used for the preparation of all solutions. The concentrations of $\mathrm{H}_{2} \mathrm{SO}_{4}$ used for the study were 1.0, 1.5, 2.0 and $2.5 \mathrm{M}$ while the concentrations of the inhibitor were $3 \times 10^{-4}, 6 \times 10^{-4}, 9 \times 10^{-4}, 1 \times 10^{-3}$ and $3 \times 10^{-3} \mathrm{~mole} / \mathrm{L}$. These were respectively dissolved in $2.5 \mathrm{M} \mathrm{H}_{2} \mathrm{SO}_{4}$.

\section{Gasometric method}

Hydrogen evolution measurements were carried out at 303 and $333 \mathrm{~K}$ as described in literature ${ }^{12-14}$. From the volume of hydrogen evolved per minutes, inhibition efficiency (\%I), and degree of surface coverage $(\theta)$ were calculated using equation 1 and 2 respectively. 


$$
\begin{gathered}
\% I=\left(1-\frac{V_{H t}^{1}}{V_{H t}^{o}}\right) x 100 \\
\theta=1-\frac{V_{H t}^{1}}{V_{H t}^{o}}
\end{gathered}
$$

Where $V_{H t}^{\prime}$ is the volume of hydrogen evolved at time $t$ for inhibited solution and $V_{H t}^{0}$ is the volume of hydrogen evolved at time t for uninhibited solution.

\section{Thermometric method}

This was also carried out as reported elsewhere ${ }^{13}$. From the rise in temperature of the system per minutes, the reaction number $(\mathrm{RN})$ and inhibition efficiency were calculated using equation 3 and 4 respectively:

$$
\begin{aligned}
R N\left({ }^{\circ} \mathrm{C} / \mathrm{min}\right) & =\frac{T_{m}-T_{i}}{t} \\
\% I & =\frac{R N_{a q}-R N_{w i}}{R N_{a q}} \times 100
\end{aligned}
$$

Where $T_{m}$ is the maximum temperature attained by the system, $T_{i}$ is the initial temperature, $t$ is the time. $R N_{a q}$ and $R N_{w i}$ are the reaction numbers for the blank and inhibited solutions respectively.

\section{Results and Discussion}

Table 1 shows values of reaction numbers $(\mathrm{RN})$ and corrosion rate $(\mathrm{CR})$ of mild steel in various concentrations of $\mathrm{H}_{2} \mathrm{SO}_{4}$. The results indicated that the corrosion rate of mild steel increases as the concentration of $\mathrm{H}_{2} \mathrm{SO}_{4}$ increases. Figure 1 shows the variation of volume of hydrogen gas evolved with time during the corrosion of mild steel in various concentrations of $\mathrm{H}_{2} \mathrm{SO}_{4}$.

Table 1. Corrosion rate $\left(\mathrm{cm}^{3} /\right.$ minute) and reaction number $\left({ }^{\circ} \mathrm{C} /\right.$ minute $)$ for the corrosion of mild steel in $\mathrm{H}_{2} \mathrm{SO}_{4}$

\begin{tabular}{cccc}
\hline Conc. of $\mathrm{H}_{2} \mathrm{SO}_{4}, \mathrm{~mol} / \mathrm{L}$ & $\mathrm{CR}(303 \mathrm{~K})$ & $\mathrm{CR}(333 \mathrm{~K})$ & $\mathrm{RN}(303 \mathrm{~K})$ \\
\hline 1.0 & 0.175 & 1.18 & 0.0167 \\
1.5 & 0.180 & 2.23 & 0.0200 \\
2.0 & 0.220 & 2.54 & 0.0267 \\
2.5 & 0.380 & 2.94 & 0.0500 \\
\hline 7.0 & & & \\
\hline
\end{tabular}

Figure 1. Variation of the volume of hydrogen gas evolved $i^{\text {th }}$ time for the corrosion of mild steel in various concentrations of tetraoxosulphate(VI) acid 
The figure confirms that the rate of corrosion of mild steel in $\mathrm{H}_{2} \mathrm{SO}_{4}$ increases as the concentration of the acid increases. In the presence of various concentrations of tarivid, the corrosion rates of mild steel (Table 2) were found to be reduced indicating that tarivid retarded the rate of corrosion of mild steel.

Table 2. Corrosion rate $\left(\mathrm{cm}^{3} /\right.$ minute) and reaction number $\left({ }^{\circ} \mathrm{C} /\right.$ minute $)$ for the corrosion of mild steel in $2.5 \mathrm{M} \mathrm{H}_{2} \mathrm{SO}_{4}$ containing various concentrations of tarivid

\begin{tabular}{cccc}
\hline Conc. of tarivid, $\mathrm{mol} / \mathrm{L}$ & $\mathrm{CR}, 303 \mathrm{~K}$ & $\mathrm{CR}, 333 \mathrm{~K}$ & $\mathrm{RN}, 303 \mathrm{~K}$ \\
\hline $3 \times 10^{-4}$ & 0.085 & 2.1800 & 0.0140 \\
$6 \times 10^{-4}$ & 0.065 & 2.1133 & 0.0148 \\
$9 \times 10^{-4}$ & 0.060 & 1.6670 & 0.0152 \\
$1 \times 10^{-3}$ & 0.040 & 1.5533 & 0.0167 \\
$3 \times 10^{-3}$ & 0.020 & 1.3467 & 0.0167 \\
\hline
\end{tabular}

Figures 2 and 3 show the variation of volume of hydrogen gas evolved with time for the corrosion of mild steel in $\mathrm{H}_{2} \mathrm{SO}_{4}$ containing various concentrations of tarivid. The figures revealed that the volume of hydrogen gas evolved by the blank solution (i.e $2.5 \mathrm{M} \mathrm{H}_{2} \mathrm{SO}_{4}$ ) were higher than the volumes evolved by the same solutions containing various concentrations of tarivid. This indicates that tarivid inhibited the corrosion of mild steel in $\mathrm{H}_{2} \mathrm{SO}_{4}$. Volumes of hydrogen gas evolved were also found to increase as the temperature of the corrodent increases indicating that the inhibition efficiency of tarivid is affected by temperature.

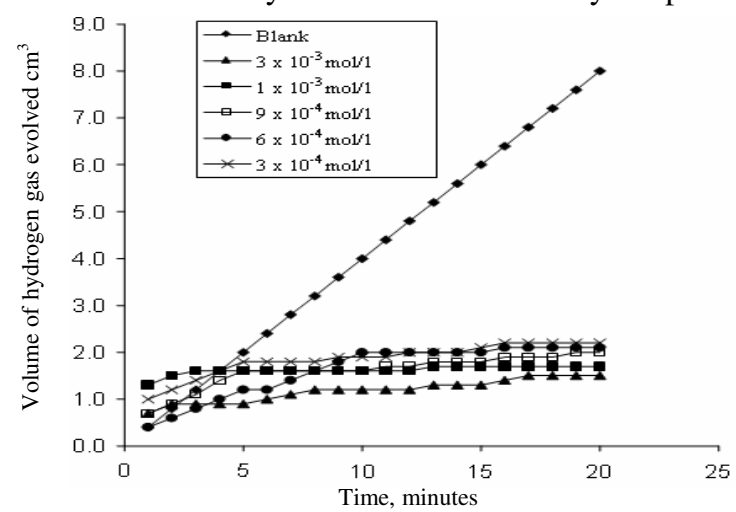

Figure 2. Variation of volume of hydrogen gas evolved with time during the inhibition of the corrosion of mild steel by various concentrations of tarivid

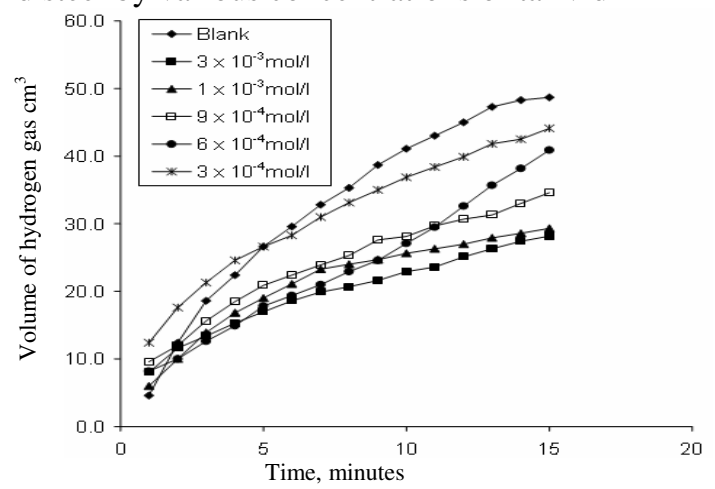

Figure 3. Variation of volume of hydrogen gas evolved with time during the inhibition of the corrosion of mild steel by various concentrations of tarivid at $333 \mathrm{~K}$ 
Table 3 shows the inhibition efficiencies of various concentrations of tarivid for the corrosion of mild steel in $\mathrm{H}_{2} \mathrm{SO}_{4}$. The results indicated that the inhibition efficiency of tarivid decreases as the temperature increases indicating that tarivid is an adsorption inhibitor for mild steel corrosion ${ }^{5}$. For a physical adsorption mechanism, inhibition efficiency of an inhibitor decreases with temperature while for a chemical adsorption mechanism, values of inhibition efficiency increase with temperature. The values of the inhibition efficiency obtained at $303 \mathrm{~K}$ for the two methods used are comparable. In order to study the effect of temperature on the inhibited corrosion reaction of mild steel, Arrhenius equation was used (equation 5) ${ }^{15,16}$ :

$$
\mathrm{CR}=\mathrm{A} \exp \left(-\mathrm{E}_{\mathrm{a}} / \mathrm{RT}\right)
$$

Taking logarithm of both sides of equation 5, equation 6 is obtained:

$$
\log \mathrm{CR}=\log \mathrm{A}-\mathrm{E}_{\mathrm{a}} / \mathrm{RT}
$$

Table 3. Values of inhibition efficiency (\%I) of tarivid during the inhibition of mild steel corrosion.

\begin{tabular}{cccc}
\hline \multirow{2}{*}{$\begin{array}{c}\text { Conc. of tarivid, } \\
\mathrm{mol} / \mathrm{L}\end{array}$} & \multicolumn{2}{c}{ Gasometric } & Thermometric \\
\cline { 2 - 4 }$\% \mathrm{I}, 303 \mathrm{~K}$ & $\% \mathrm{I}, 333 \mathrm{~K}$ & $\% \mathrm{I}, 303 \mathrm{~K}$ \\
\hline $3 \times 10^{-4}$ & 77.63 & 25.85 & 74.55 \\
$6 \times 10^{-4}$ & 82.89 & 28.12 & $75 . .00$ \\
$9 \times 10^{-4}$ & 84.21 & 43.31 & 75.00 \\
$1 \times 10^{-3}$ & 89.47 & 47.17 & 77.34 \\
$3 \times 10^{-3}$ & 94.74 & 54.20 & 78.44 \\
\hline
\end{tabular}

Where CR is the corrosion rate of mild steel. A is Arrhenius constant or pre-exponential factor, $E_{a}$ is the activation energy of the reaction, $R$ is the gas constant and $T$ is the temperature. Considering a change in temperature from $303 \mathrm{~K}\left(\mathrm{~T}_{1}\right)$ to $333 \mathrm{~K}\left(\mathrm{~T}_{2}\right)$, the corresponding values of the corrosion rates at these temperatures are $\mathrm{CR}_{1}$ and $\mathrm{CR}_{2}$ respectively. Inserting these parameters into equation 6 , equation 7 is obtained:

$$
\log \left(\mathrm{CR}_{2} / \mathrm{CR}_{1}\right)=\mathrm{E}_{\mathrm{a}} / 2.303 \mathrm{R}\left(1 / \mathrm{T}_{1}-1 / \mathrm{T}_{2}\right)
$$

Values of $E_{a}$ calculated from equation 7 are recorded in Table 4 . These values are higher than the value of $27.28 \mathrm{~kJ} / \mathrm{mol}$ obtained for the blank indicating that the corrosion reaction of mild steel is retarded by tarivid. It also supports the phenomenon of physical adsorption. Values of heat of adsorption of tarivid on mild steel surface were calculated ${ }^{12-14}$ using equation 8:

$$
\mathrm{Q}_{\mathrm{ads}}=2.303 R\left[\log \left(\theta_{2} / 1-\theta_{2}\right)-\log \left(\theta_{1} / 1-\theta_{1}\right)\right] \times\left(\mathrm{T}_{1} \times \mathrm{T}_{2}\right) /\left(\mathrm{T}_{2}-\mathrm{T}_{1}\right)
$$

Table 4. Some thermodynamic parameters for the adsorption of tarivid on mild steel surface

\begin{tabular}{ccc}
\hline Conc. of tarivid, mol/L & $\mathrm{E}_{\mathrm{a}}, \mathrm{kJ} / \mathrm{mol}$ & $\mathrm{Q}_{\mathrm{ads}}, \mathrm{kJ} / \mathrm{mol}$ \\
\hline Blank & 27.28 & \\
$3 \times 10^{-4}$ & 39.05 & -34.19 \\
$6 \times 10^{-4}$ & 41.89 & -32.66 \\
$9 \times 10^{-4}$ & 40.03 & -31.05 \\
$1 \times 10^{-3}$ & 44.02 & -45.05 \\
$3 \times 10^{-3}$ & 50.61 & -53.53 \\
\hline
\end{tabular}

Calculated values of $\mathrm{Q}_{\mathrm{ads}}$ (Table 3) were negative and ranged from -31.04 to-53.53 $\mathrm{kJ} / \mathrm{mol}$ indicating that the adsorption of tarivid on mild steel surface is exothermic. It can also be stated that since the reaction was carried out at constant pressure, values of $\mathrm{Q}_{\text {ads }}$ obtained during the study ${ }^{2-5,17-18}$ approximated those of enthalpy of adsorption $\left(\Delta \mathrm{H}_{\mathrm{ads}}\right)$. 
Adsorption isotherms are very important in understanding the mechanism of inhibition of corrosion reaction. The most frequently used adsorption isotherms are Frumkin, Temkin, Freundlich, Flory Huggins, Bockris -Swinkel, El-Awardy and Langmuir isotherms. All these isotherms can be represented as follows,

$$
f(\theta, \mathrm{x}) \exp (-2 \mathrm{a} \theta)=\mathrm{k} \mathrm{C}
$$

Where $f(\theta, \mathrm{x})$ is the configuration factor which depends upon the physical model and the assumptions underlying the derivation of the isotherm. $\theta$ is the degree of surface coverage, $\mathrm{C}$ is the inhibitor concentration in the electrolyte, $\mathrm{x}$ is the size ratio, a is molecular interaction parameter and $\mathrm{k}$ is the equilibrium constant of the adsorption process. Adsorption of tarivid on the surface of mild steel is best explained by Langmuir isotherm. Langmuir isotherm is an ideal isotherm for physical or chemical adsorption where there is no interaction between the adsorbate and the adsorbent ${ }^{5}$. Assumptions of Langmuir relate the concentration of the adsorbate in the bulk of the electrolyte $(\mathrm{C})$ to the degree of surface coverage $(\theta)$ according to equation $10^{19,20}$ :

$$
\mathrm{C} / \theta=1 / \mathrm{k}+\mathrm{C}
$$

Where, $\mathrm{k}$ is the equilibrium constant of adsorption. By plotting values of $\log \mathrm{C} / \theta$ versus values of $\log C$, straight lines graphs were obtained (Figure 4). Applicability of Langmuir adsorption isotherm to the adsorption of tarivid on the surface of mild steel indicates that there is no interaction between the adsorbate and adsorbent. Values of free energy of adsorption of tarivid on mild steel surface were calculated using the following equation ${ }^{2-4}$ :

$$
\Delta \mathrm{G}_{\mathrm{ads}}=-2.303 \mathrm{RT} \log (55.5 \mathrm{~K})
$$

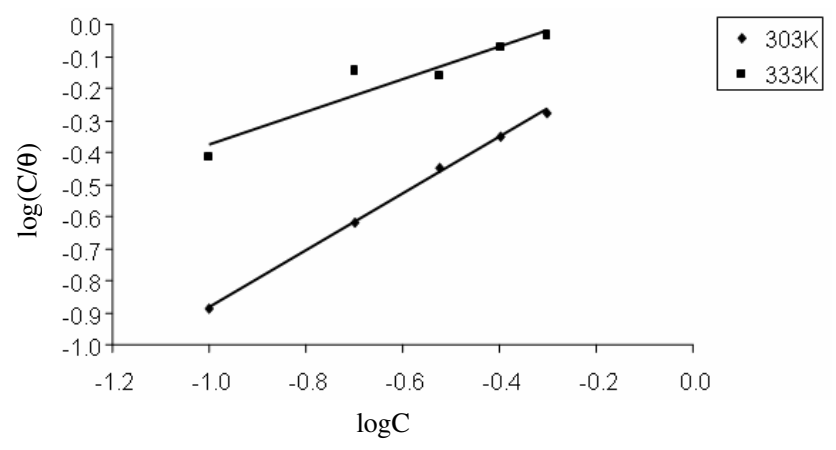

Figure 4. Langmuir isotherm for the adsorption of tarivid on the surface of mild steel

Where, $\mathrm{K}$ is the adsorption equilibrium constant. Calculated values of $\Delta \mathrm{G}_{\mathrm{ads}}$ are recorded in Table 5. These values are negative and are less than the threshold value of -40 $\mathrm{kJ} / \mathrm{mol}$ confirming that the adsorption of tarivid on mild steel is spontaneous and that physical adsorption mechanism is applicable. Comparing the degree of linearity of Langmuir adsorption isotherms as measured by values of $\mathrm{R}^{2}$ (Table 5), it is seen that Langmuir adsorption isotherm is best applicable at $303 \mathrm{~K}$ than at $333 \mathrm{~K}$. This confirms that the adsorption behaviour of the inhibitor is strongly influenced by temperature. Also value of the slope at $303 \mathrm{~K}$ is greater than the value obtained at $333 \mathrm{~K}$ indicating that the strength of the attractive behaviour of the inhibitor decreases with temperature.

Table 5. Langmuir adsorption parameters

\begin{tabular}{ccccc}
\hline Temperature, $\mathrm{K}$ & Slope & $\log \mathrm{K}$ & $\mathrm{R}^{2}$ & $\Delta \mathrm{G}_{\mathrm{ads}}, \mathrm{kJ} / \mathrm{mol}$ \\
\hline 303 & 0.8856 & 0.0007 & 0.9985 & -11.94 \\
333 & 0.5103 & 0.1328 & 0.9101 & -11.20 \\
\hline
\end{tabular}




\section{Conclusion}

From the study, the following conclusions are made:

i) Tarivid acts as a good inhibitor for mild steel corrosion.

ii) Inhibition efficiency of tarivid depends on concentration and temperature.

iii) Inhibition of mild steel corrosion by tarivid is thermodynamically feasible.

iv) The mechanism of inhibition of mild steel corrosion by tarivid is by physical adsorption according to the classical adsorption isotherm of Langmuir.

\section{References}

1. Abdallah M, Corros Sci., 2004, 46, 1981.

2. Ashassi-Sorkhabi H, Ghasemi Z and Seifzadeh B, Appl Surf Sc., 2005, 29, 408.

3. Ashassi-Sorkhabi H, Majidi M R and Seyyedi K, Appl Surf Sci., 2004, 225, 76.

4. Ashassi-Sorkhabi H, Shaabani B and Seifzadeh B, Appl Surf Sci., 2005, 239(2),154.

5. Eddy N O, Inhibition of Corrosion of Mild Steel by Some Antibiotics, Ph D Thesis, University of Calabar, Nigeria, 2008.

6. Abdallah M, Corros Sci., 2002, 44(4), 717.

7. Abdallah M, Corros Sci., 2004, 46, 1981.

8. El-Naggar M M, Corros Sci., 2007, 49, 2226-2236.

9. Solmaz R, Kardas G, Yazici B and Erbil M, Prot Met., 2005, 41(6), 581-585.

10. Sing W T, Lee C L, Yeo S L, Lim S P and Sim M M, Bioorg Med Chem Lett., 2001, 11(2), 91.

11. El-Dissouky A, El-Bindary A A, El-Soubati A Z and Hilali A S, Spectrochim Acta, 2001, A57, 1163.

12. Oguzie E E, Pigment Resin Technol., 2006, 35(6), 334-340.

13. Umoren S A, Ebenso E E, Okafor P C and Ogbobe O, Pigment Resin Technol., 2006, 35(6), 346-352.

14. Umoren S A, Obot I B, Ebenso E E, Okafor P C, Ogbobe O and Oguzie E E, AntiCorrosion Methods and Materials, 2006, 53(5), 277-282 and reference cited therein.

15. Acharya S and Upadhyay S N, Trans Indian Inst Met., 2004, 57(3), 297-306.

16. Yurt A, Bereket G, Rivrak A, Balaban A and Erk B, J Appl Electrochem., 2005, 35, 1025.

17. Atkins P W, Physical chemistry, $7^{\text {th }}$ Edition, Oxford University Press, London, 2002, 76 .

18. Sharma K K and Sharma L K, A Textbook of Physical Chemistry, $4^{\text {th }}$ revised Edition, India: Vikas Pub. House, PVT Ltd., 2004, 127-236.

19. Emregul K C, Akay A A and Atakol O, Mater Chem Phys., 2005, 93, 325-329.

20. Emregul K C Duzgun E and Atakiol O, Corros Sci., 2006, 48(4), 3243-3260. 


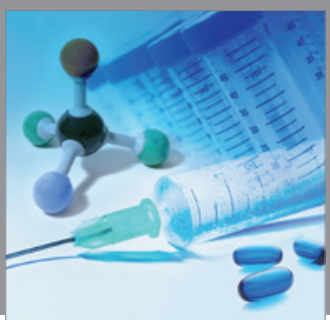

International Journal of

Medicinal Chemistry

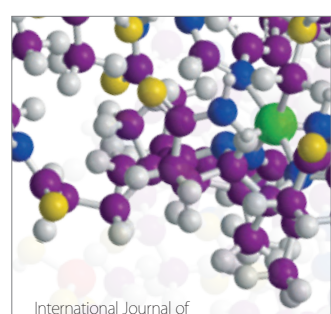

Carbohydrate Chemistry

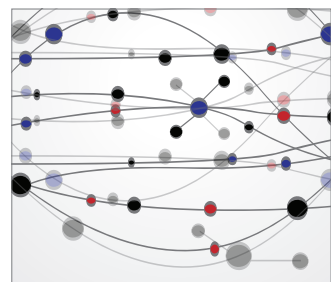

The Scientific World Journal
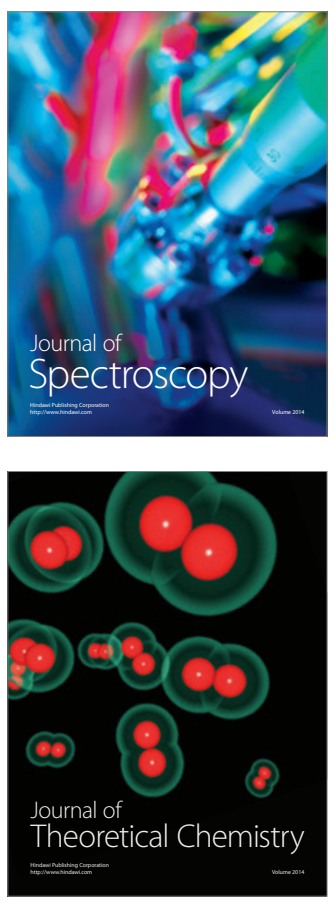
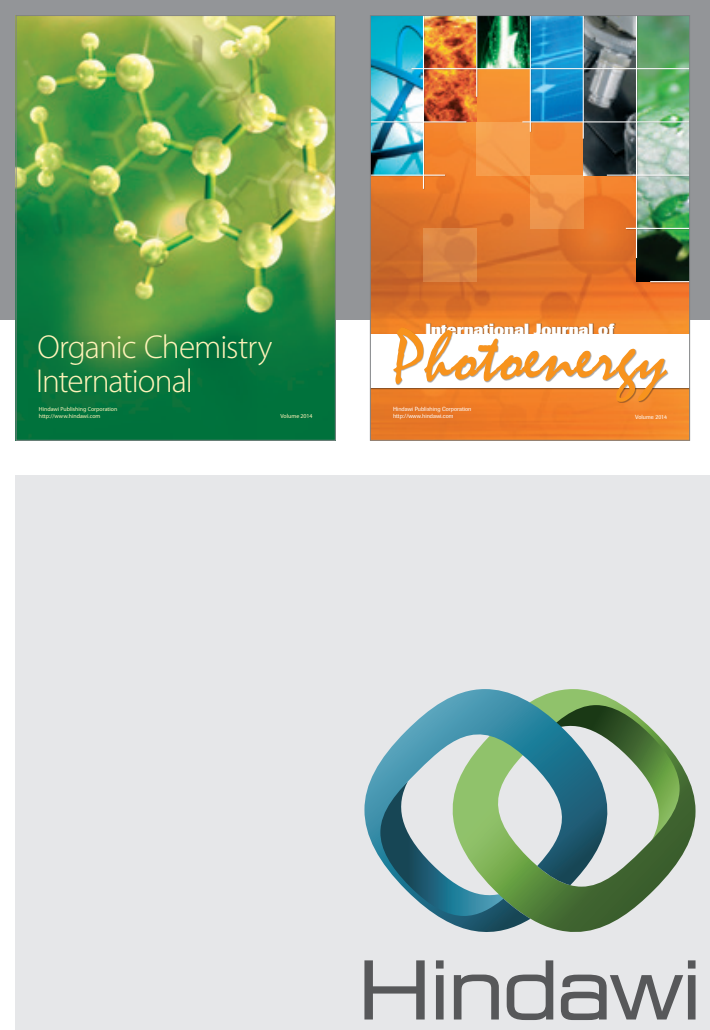

Submit your manuscripts at

http://www.hindawi.com
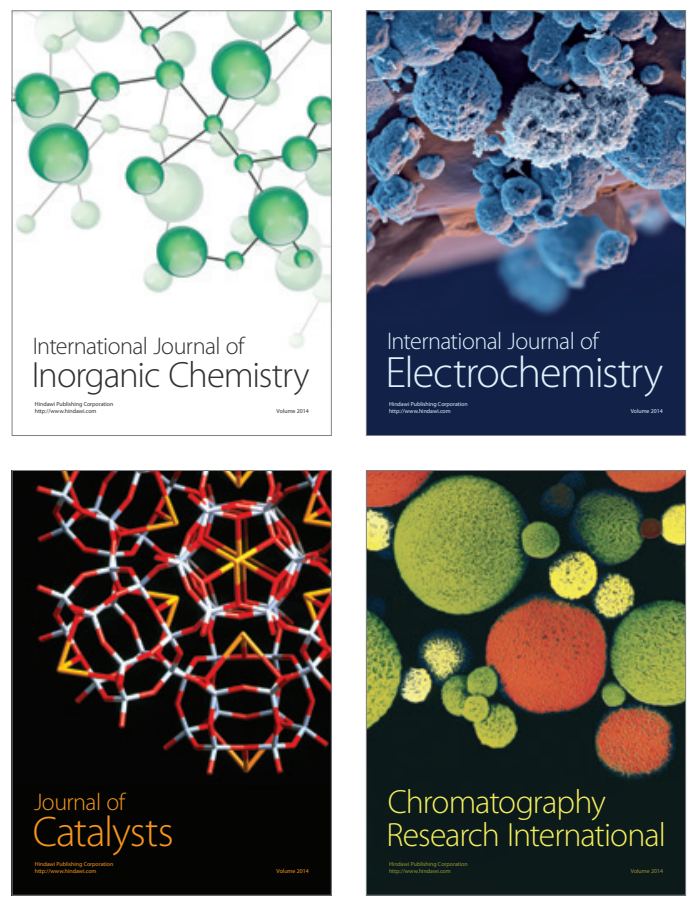
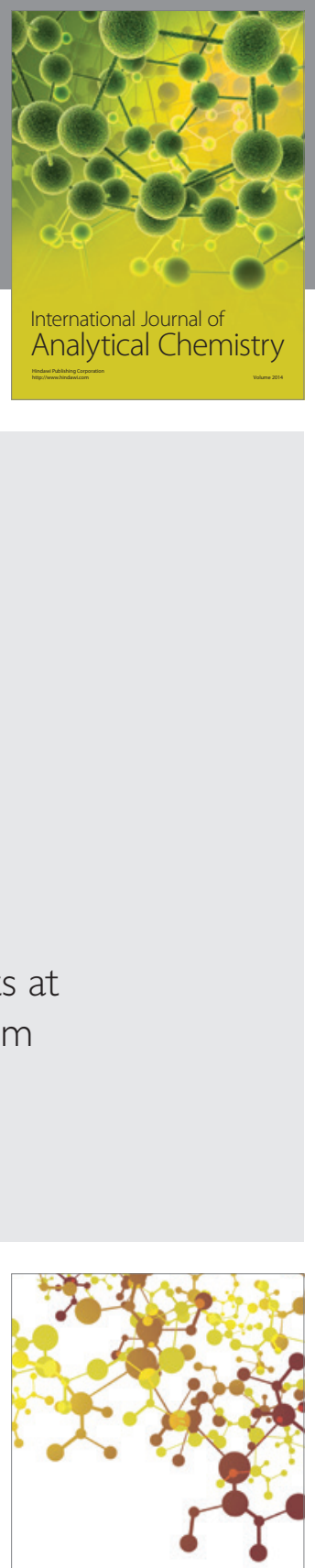

Journal of

Applied Chemistry
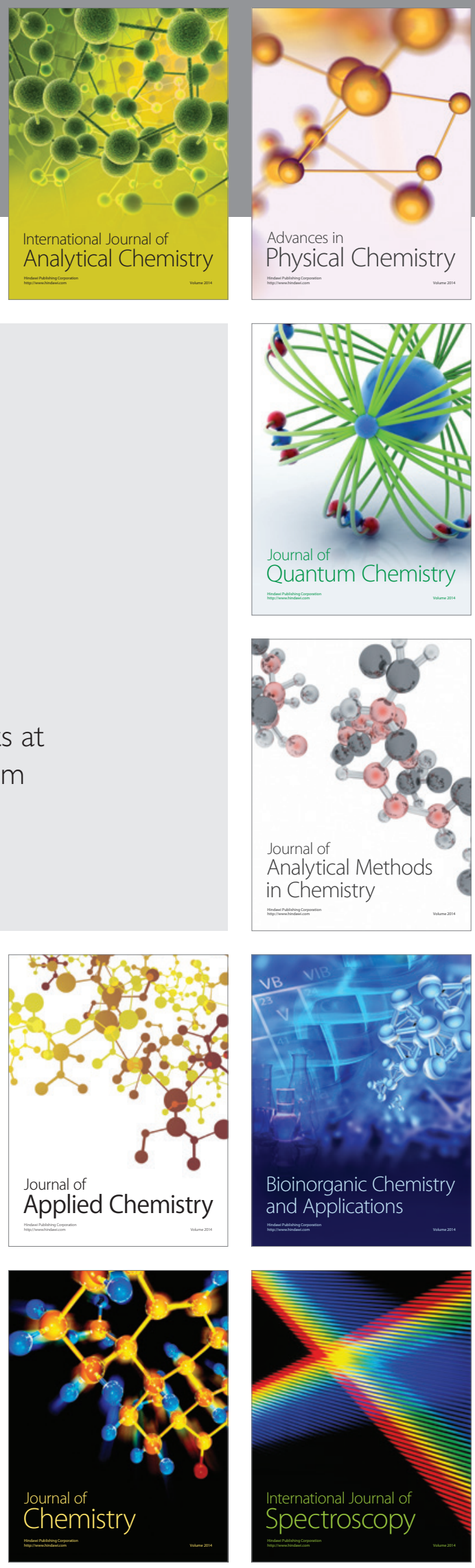